\title{
MUTUAL EXPECTATIONS IN THE POSTGRADUATE DOCTORAL SUPERVISORY RELATIONSHIP
}

\section{Hesta Friedrich-Nel \& Joyce MacKinnon}

\section{INTRODUCTION}

Creating a cadre of scholars for a knowledge society in South Africa is critical for the development of the country. One way in which this need can be addressed is to produce doctoral students capable of contributing to knowledge production. An integral element in doctoral education is the formation of a successful supervisory relationship between the doctoral supervisor and the doctoral student. In a positive and successful relationship, the expectations of the student and the supervisor are in alignment. However, it is common to see some disparities in the expectations. Although the disparity in expectations cannot be linked to a specific research supervision model, the assumption is that there may be an association when one or two supervisors and one student work together in what is referred to as the 'traditional apprenticeship model of supervision'. Strategies such as the use of open and continuous communication, the provision of timely and constructive feedback and the creation of a trusting environment are useful in addressing the disparities in the expectations of both supervisor and student.

The literature on doctoral education and postgraduate supervision refers to the supervisory relationship in a number of ways. For example, Bartlett and Mercer (2000:196) call the relationship "complex" because the process may appear to participants to be inflexible and individualistic. These authors also mention the possibility of a power relationship created by the "knowing" supervisor engaging with the "unknowing student" (Bartlett \& Mercer 2000:196). Other descriptions such as "unfinished business" (Green 2005:151) or "an uncertain practice" (Grant 2005:337) are also used to emphasise the possible challenges of this supervisory relationship. Adkins (2009) adds a perspective to the relationship by referring to 


\section{PART THREE - CHANGING EXPECTATIONS OF POSTGRADUATE STUDENTS AND SUPERVISORS}

the possible mismatched expectations between the postgraduate supervisor and the student.

To illustrate the differing perspectives of the supervisory relationship, two former doctoral students offered comments, which are reproduced verbatim here (University of Warwick 2007):

$\mathrm{A} \mathrm{PhD} \mathrm{is} \mathrm{very} \mathrm{different} \mathrm{from} \mathrm{a} \mathrm{master's} \mathrm{course,} \mathrm{given} \mathrm{that} \mathrm{a} \mathrm{PhD}$ is a very private programme managed between you and your supervisor(s). You are supposed to propose your own topic, design your own research plan, and eventually and, most importantly, develop your own ideas and argument. In the process, you will have guidance and advice from one or two of your supervisors at arm's length. On the other hand, doing a $\mathrm{PhD}$ is not that lonely and miserable. You will have lots of opportunities to discuss and share ideas with fellow research students, going to conferences and meeting people in the same or a similar field.

For me, the most important thing for a PhD student is to confirm one's interest in a particular topic and one's reasons for pursuing a PhD. In fact, the life of a PhD student is daunting: loneliness, pressure, isolation and boredom are always close at hand. Of course, quality supervision is key for a PhD student. Many PhD students face difficulty in dealing with their supervisors, or feel unsatisfied with their supervision. However, I was very lucky on this point. My supervisor was always supportive of me and provided much useful feedback for the improvement of my thesis. I really learned a great deal from supervision, such as how to conduct reliable research, how to interpret and incorporate various theories and how to write a better thesis.

These graduates reflected on their successful doctoral journey and the lessons learned from the process and from the supervisor in the same way that Phillips and Puh (2005) refer to the graduate student journey as one of a series of challenges with support from the supervisor. Both Phillips and Puh (2005) and Watts (2010) acknowledge the important role of the supervisor in supporting the student and creating a successful supervisory relationship. The focus of this relationship is for the supervisor to be the academic guide for the student and to serve as a mentor. However, even with the support of the supervisor, students experience challenges.

The series of challenges are associated with the student's feelings of "isolation", "frustration" and "uncertainty" (Phillips \& Puh 2005:72, 76, 84). The positive and negative emotions and highs and lows that students experience during the attainment of the doctoral degree may also affect some of the other student challenges (Morrison-Saunders, Moore, Hughes \& Newsome 2010), such as their ability to accept feedback and constructive criticism (Sambrook, Stewart \& Roberts 2008). Another challenge is the ability of the student to manage time effectively 
during the research process, for instance in preparing the research proposal, doing the research project, finalising the chapters of the thesis and completing the viva (Leonard 2010; Morrison-Saunders et al 2010). Additional student challenges may include balancing being dependent on the supervisor with independence from the supervisor, being able to assume a certain level of responsibility for research tasks and outcomes, and preparedness to conduct and complete research (Conrad 2003). These challenges may even become more common as the growing number of postgraduate students have access to a limited number of supervisors (Conrad 2003).

It is also not uncommon for supervisors to share similar challenges while guiding the student through the attainment of a doctoral degree. Based on the work of Backhouse (2009), many of the challenges that postgraduate supervisors face are related to increasing academic demands, a lack of preparedness to provide postgraduate supervision, and limited human and other resources. More recently, complex issues, such as cultural diversity, gender, age and experience, work-life balance, diverse life styles, and disability have been added to the agenda of the doctoral supervisor (Phillips \& Puh 2005). To provide this personal guidance can be a challenge since the supervisor will need to commit time to read the student's drafts and chapters in order to provide constructive feedback as well as to meet with the student - either face-to-face or online (University of Cambridge 2015:6).

In many instances, the aforementioned challenges arise from assumptions and perceptions that originate from the disparity of expectations between the supervisor and the student. Taking note of the mismatched expectations, the challenges and the complex supervisory relations, we propose strategies that can be implemented to result in a successful supervisory relationship. To support our findings we present an example of a case study that focused on the expectations of the supervisor and the student with regard to the doctoral supervisory relationship. While the experienced postgraduate supervisor may be familiar with the content of this chapter, the novice and postgraduate supervisor and/or mentor may find the information useful to direct early discussions with postgraduate students and in clarifying mutual expectations.

\section{EXPECTATIONS IN THE SUPERVISORY RELATIONSHIP}

It is thus logical to assume that the supervisor and the student need to work together as a team to engage in doctoral education and prepare the thesis (Maxwell \& Smyth 2011). For this reason it is important to focus on strategies to support how the expectations from both parties can be met. Leonard (2010) argues that the expectations associated with postgraduate supervision are threefold, involving the 


\section{PART THREE - CHANGING EXPECTATIONS OF POSTGRADUATE STUDENTS AND SUPERVISORS}

university, the supervisor and the student. While the university has to provide the physical, financial and procedural support for doctoral education (Leonard 2010), this chapter will concentrate on the expectations associated with the supervisor and the student.

The first step in addressing possible mismatched expectations between the supervisor and the student is to identify the perceptions and assumptions associated with the supervisory relationship from both perspectives. An essential element for the successful outcome in doctoral education is early contact between the supervisor and the student for the purpose of outlining the expectations of both parties involved. In this section, the role of communication, the creation of a positive supervisory relationship and the mentoring role of the supervisor will be highlighted as elements in creating a successful supervisory relationship.

Communication is a critical element in a successful supervisory relationship; it involves feedback from both the supervisor and the student, sharing the criteria for quality (such as in writing) and establishing a positive research culture. Feedback on the work (such as the proposal, research progress and draft chapters) is crucial not only in shaping the end product, but also in developing the personal attributes of the student necessary for success in doctoral attainment. The student requires feedback to identify both the strengths and the problem areas in the work, and to receive suggestions for improvements and so assist with progress. Students expect effective feedback and constructive criticism on their work (Phillips \& Puh 2005).

Leonard (2010) supports departmental seminars bringing students together to eliminate their feelings of isolation, explain how feedback will be given and address additional student questions. Guerin, Picard and Green (2014) propose thesis writing groups to help students to work together in groups. They also suggest that the groups be heterogeneous to expose students to different cultures and ways of thinking. Aspland, Edwards, O'Leary and Ryan (1999) designed a rubric to facilitate specific feedback from the doctoral student. Guided by this instrument, the supervisor and the student can direct the focus of their discussion sessions on the needs and expectations of the student.

Students expect supervisors to be friendly and supportive. Authors such as Pearson and Brew (2002) as well as Malfroy (2005) suggest that a positive and trusting relationship and environment can counteract the challenges and disjunction in expectations between the supervisor and the student. A strategy in maintaining quality supervisor-student relationships is for individual supervisors to schedule occasional focus group meetings with all of their doctoral students. The feedback obtained from 
the students can then assist in shaping the relationship and the doctoral education process (Aspland et al 1999).

In a positive supervisory relationship, the student should feel free to consult the supervisor (in person, by e-mail or telephone) any time, but in particular as soon as he or she experiences challenges (Manathunga 2007). In a study reported by Conrad (2003), students suggested strategies to achieve a positive relationship, such as having a structured doctoral programme, being part of a research community, using a group supervision model rather than a one-on-one supervision model, establishing peer support groups and creating student teams to maintain the positive relationship. Hemer (2012) recommends a neutral space such as a café or coffee shop for meetings between the supervisor and the student. She is of the opinion that these spaces communicate a message of availability and informality.

Assuming the role of mentor, the supervisor also needs to assist the students in developing personal attributes, such as the ability to communicate effectively, think critically, practise self-discipline, be resilient, work independently and manage time effectively. A helpful tool to assist the supervisor in assessing the personal attributes and competencies of the student at the start of the research process is the Vitae Researcher Development Framework (Vitae: Realising the potential of researchers 2016). This tool assists in planning the skills development activities necessary for successful doctoral completion (El Gaidi 2014) as well as in monitoring through selfevaluation. The ideal situation is created when the student and supervisor set specific goals at the beginning of the doctoral education process and then periodically (for example every six months) reflect on the goal attainment during their meetings (University of Cambridge 2015). Taking care of the development of the student may set the stage for a supportive research environment and research culture to enable the student to develop as a researcher (Trigwell 2010), as well as to be a contributing member of the knowledge society.

\section{RESULTS OF A CASE STUDY}

As noted in the introduction to this chapter, a qualitative case study was used for the research reported here. The case study that followed a structured interview approach involved the perceptions of postgraduate doctoral supervisors and doctoral students with regard to supervision and was conducted at a research-intensive university in the USA. Although the study was performed in the USA, the findings are in alignment with international research on this topic and for that reason are transferrable to the South African context. 


\section{PART THREE - CHANGING EXPECTATIONS OF POSTGRADUATE STUDENTS AND SUPERVISORS}

At the time of the research, the predominant supervisory model at this university was the apprenticeship model where one or two supervisor(s) work with an individual doctoral student. A total of 23 postgraduate supervisors and 15 doctoral students from various disciplines and schools volunteered to participate in the structured interviews (Table 10.1). The students were at various stages in the doctoral process, from just completing coursework through to just receiving approval to graduate.

TABLE 9.1 Participants in the structured interviews

\begin{tabular}{|l|c|c|}
\hline Discipline/School & Supervisor & Student \\
\hline Business & 1 & 0 \\
\hline Dental & 2 & 4 \\
\hline Education & 3 & 2 \\
\hline Health and Rehabilitation Sciences & 2 & 0 \\
\hline Graduate School & 5 & 0 \\
\hline Law & 0 & 2 \\
\hline Library & 1 & 0 \\
\hline Medicine & 4 & 1 \\
\hline Nursing & 2 & 2 \\
\hline Psychology & 2 & 0 \\
\hline Social Work & 1 & 4 \\
\hline Total & 23 & 15 \\
\hline
\end{tabular}

The questions used in the structured interviews were first piloted with a select group of supervisors and students. Examples of questions to the supervisors were related to what supervisors expected from their students and whether the supervisors communicated the expectations explicitly. Questions to the students were related to what they expected from the research supervisor, whether expectations were discussed at any time and whether the students were familiar with the expectations. The researcher captured the information electronically during the interview, and participants verified the information via e-mail. Data analysis and interpretation were conducted according to the process outlined by Denscombe (2007). The data were grouped according to the questions asked in the structured interview. The data were then coded and categorised. Subsequently, themes and relationships were identified. Finally, some generalised conclusions were reached based on the relationships and themes identified.

\section{Doctoral supervisor expectations}

The responses of the supervisors were grouped according to the themes that emerged from the findings: 
- the personal and professional qualities expected from the students;

- expectations regarding knowledge and skills in terms of the research process; and

- expectations regarding the final outcome of the research process.

Regardless of the discipline or school, students were expected to be problem solvers, disciplined, innovative, engaged, reflective, motivated and comfortable in discussing their own issues with the supervisor. According to one of the supervisors:

High expectations in working independently - how to work on their own, and when they have a question they can come and ask me any time. I tell them that I need them to be independent and work first by themselves. I discuss the expectations with them, and I tell them to talk to current students to find out how it is working with me because I am busy, and I travel a lot, so we need to work around my busy schedule.

With regard to engaging in research leading to a thesis, supervisors expected students to identify a research problem, formulate the research question, and design the methodology. Students were also expected to study the literature, schedule time to write, create innovative ideas, and be in a 'scholarship mode'. The majority of the supervisors who participated in the study expected students to work hard, become lifelong learners, accept constructive criticism and feedback, be committed to the research process, keep the supervisor informed about progress, complete the proposal and the thesis, and attain their degree. Supervisors also expected students to publish and present the results of their research at academic meetings. One supervisor stated, "I expect them to be in the lab working on the project; the main role is to get the project done, to be up on the latest literature in their field." Another explained, "PhD students are very well aware of what is expected of them along the way - to demonstrate a mastery/superior level of expertise in their chosen discipline/ area." A third noted:

I explain the process that we will be following and how I will be giving the feedback. I discuss this on an ongoing basis and sometimes refer back to discussions, i.e. remember when we discussed ... I discuss with them what I expect, that is to work hard, to learn to accept constructive criticism, be committed during the research process, do their best, and keep their eye on the prize, namely getting the degree. I also expect the students to acquire the skills and attributes of a successful colleague turn them into productive, happy contributors.

Over and above degree attainment, supervisors expected that students would be prepared to enter the academic community and to contribute to knowledge production. One supervisor stated, "It's important to keep in mind the goal of 


\section{PART THREE • CHANGING EXPECTATIONS OF POSTGRADUATE STUDENTS AND SUPERVISORS}

engaging in the PhD process - to facilitate the development of an eventual faculty member."

\section{Doctoral student expectations}

The themes identified from the students' responses were grouped as supervisor guidance and feedback. Guidance included research guidance and mentorship from the supervisor as well as guidance to manage the research project. Students indicated the need for their supervisor to be a sounding board for ideas and responses. Students also needed guidance from the supervisor on the presentations of the proposal and the viva. One student stated, "Guidance on the process. I do not ask her questions about my specific research method ... but she does a lot of cheerleading for me." Another student responded, "Guide me through my research project; help me avoid crucial mistakes in the design of my study."

The students indicated that they needed their supervisor to provide leadership as well as to act as a mentor and, thus, be supportive. The students also mentioned that they needed to be treated as professionals and with respect. As such, they expected the supervisor to be professional and transparent and to understand the student growth and development that accompany the research process. They also wanted the supervisor to provide guidance on their careers. One student explained, "Respectful of me and my work, not belittle me or my work. Constructive criticism so that I and my work can improve. Available for support." Another stated, "To teach me everything he knows about the topic and all relevant information around the topic, everything that is important for me to know about the research that I am doing."

The students were clear that they required guidance and/or support from the supervisor throughout the research process. Another stated:

... needed guidance in terms of research focus, guided me through the proposal and the research, guided me through the experiments, when he gets invites to write chapters he includes me in that and congress presentations. I benefitted from the relationship and gained experience in presenting and writing.

Students expected timely and constructive feedback from the supervisor and wanted their supervisor to adhere to agreed-upon timelines and to respect their work. One student explained:

Timely feedback - as a student I know I cannot expect her to give work back fast. So it is communicated when I will get the work back (eg will tell when she can do the work and give it back to me). 
The students also indicated that they valued the feedback from their supervisor as a means to shape their work. One student explained, "Talk through ideas, help put things in perspective and in a proper frame to be supportive of my ideas and also non-judgmental and truthful about my ideas; will give an honest opinion."

A number of students reported that their supervisors expected them to adhere to prearranged deadlines and to be flexible and able to adjust to constructive criticism of their work. One student noted, "To meet deadlines, to be respectful of the supervisor and the time schedules, to adhere to the comments on the constructive feedback, to submit my work [in a] timely [manner], and submit professional-looking work of good quality." Another stated, "Keep the supervisor informed about my progress, where I was in the process, and provide him with materials only when it is ready (not too early, when it is not yet ready). I once had the experience where I misunderstood the communication with my supervisor and I sent information too soon. He was not happy."

Students also felt that they were expected to set goals, show consistent progress with the project, grow and develop through the research process, present their research at conferences, and provide only polished work that appeared professional and of good quality to the supervisor. They felt that they had to keep the supervisor informed about their progress and to report and communicate progress, while respecting the supervisor's time schedules. One student said, "Work hard and get my time lines right and finish experiments and write my papers on time and read about the literature in my research; that is my responsibility. Make sure my project is right."

In cases where students did not understand what was expected, they asked, sometimes several times, for clarification. If required, they were expected to seek assistance to improve on necessary skills (eg written communication). Both the supervisors and the students indicated that communicating expectations needed to be a constant and ongoing process and that expectations may change as the research process and the project develop. The supervisors indicated that, although expectations were communicated in several ways, it was important to repeat the expectations throughout the research process. One student noted, "When I had questions, I asked. When I received feedback, I went back and looked up and then asked for advice on my findings." Another student stated, "Schedule a meeting with my supervisor to ask and discuss what is not clear to me. Most of the time I get the answer to my questions [or] problems. Not always easy." Yet another student explained, "Call a meeting, have an agenda or a question, discuss the agenda or questions, and then my supervisors will discuss where things stand and my progress." 
Lessing and Schulze (2002) emphasise that the experience of a supervisor in guiding the student to independence is an important element in creating a successful supervisory relationship. The experienced supervisor knows that, at the beginning of the doctoral process, the student requires much support. This phase is followed by a time of monitoring and less interaction. When the student starts to prepare the chapters of the thesis, the engagement, communication and interaction need to increase so as to provide a supportive environment for the student (Lessing \& Schulze 2002). As such, one student noted, "At different stages, I have different expectations."

\section{Clarifying expectations}

The importance of a trusting environment in which the student feels safe to ask questions and even challenge the supervisor was clear from the findings. In this regard, Waghid (2007:184) indicates that the supervisory process is "a critical friendship" that focuses on trust, respect and imagination. This environment can facilitate important aspects in clarifying expectations, such as frequent two-way communication and effective feedback. In this regard, Grant (2005) emphasises that guidance should be motivating and instil trust and respect. Malfroy (2005) notes the need for a collegial relationship to exist between the student and the supervisor, one in which the student is viewed as a professional.

Students and their supervisors need to agree on expectations through frequent communication and clarifications. The case study participants stated that communicating of expectations should be ongoing. In this way students keep in touch with the supervisor and take responsibility for their studies. Moreover, the supervisor is then also updated about their research progress. Phillips and Puh (2005) argue that communication, planning and empathy from the supervisor will guide students in addressing their academic problems.

In addition to guidance on research, constant and effective feedback from the supervisor(s) on the student's work is essential. El Gaidi (2014) explains that effective feedback needs to facilitate the student's understanding. Helpful feedback methods entail concrete examples from the supervisor to emphasise quality principles in writing, as well as using the supervisor's own experiences to assist with explanations and thus facilitate the student's understanding (El Gaidi 2014). Feedback should further be timely and credible. In addition to addressing communication channels and thus eliminating misconceptions, feedback can add structure to the supervision process. The University of Cambridge (2015) website on PhD supervision offers suggestions to facilitate ongoing supervisor-student communication. This university suggests 
frequent discussion sessions on specific and relevant topics with the aim of strengthening the supervisory relationship. These topics include:

- sharing student and supervisor backgrounds;

- sharing role expectations and responsibilities;

- creating timelines and collaboratively setting long-term and short-term goals;

- reviewing progress;

- resolving conflict; and

- preparing for examination.

Notably, however, maintaining ongoing and effective communication and feedback may be a challenge and requires a commitment from all involved. The supervisor(s) need to schedule time to read the students' work and meet with the students to provide feedback. This may assist the supervisor(s) in recognising whether the students require specific resources, such as emotional and psychological support. Students should make sure that they honour their appointments with their supervisor and should approach the supervisor with confidence. When necessary, they need to ask for explanations or clarifications. Students also need to develop the confidence to remind the research supervisor respectfully when feedback is due. In this way, although the students respect the busy schedules of their research supervisors, they are able to participate actively in the research process and develop as professionals in the knowledge society.

\section{CONCLUSION}

In this chapter we presented strategies to mitigate the doctoral supervisor-student mismatched expectations with regard to the supervisory relationship through a review of pertinent literature and the results of a case study we conducted in 2011.

The demanding postgraduate supervision environment requires supervisors and students to clarify and discuss their expectations initially and on an ongoing and regular basis (Grant 2005). Supervisors need to create an environment for students in which they can grow and develop as professionals and in which they are free to challenge the supervisor (Malfroy 2005). A commitment is required from each of the participants in this relationship to communicate expectations initially and continually so that a safe environment in which critical thinkers and problem solvers are nurtured and respected is created.

Additional research in doctoral supervision is needed to focus on matching the personalities of the supervisor and the student as well as the way in which factors such 


\section{PART THREE • CHANGING EXPECTATIONS OF POSTGRADUATE STUDENTS AND SUPERVISORS}

as power, culture, disability, gender, race, ethnicity, culture and individual supervisory styles may affect the supervisory relationship. Ideally, bridging the disconnect in expectations between the doctoral supervisor and the student and creating positive experiences in postgraduate supervision can add to the success story of both the supervisor and the doctoral student. Ultimately, this will create a cadre of educated individuals who can add to the knowledge base critical to South Africa.

\section{REFERENCES}

Adkins BA. 2009. PhD pedagogy and the changing knowledge landscapes of universities. Higher Education Research \& Development, 28(2):165-177.

Aspland T, Edwards H, O'Leary J \& Ryan Y. 1999. Tracking new directions in the evaluation of postgraduate supervision. Innovative Higher Education, 24(2):127-147.

Backhouse JP. 2009. Doctoral Education in South Africa: Models, Pedagogies and Student Experiences. PhD thesis. Johannesburg: University of the Witwatersrand.

Bartlett A \& Mercer G. 2000. Reconceptualising discourses of power in postgraduate pedagogies. Teaching in Higher Education, 5(2): 195-204.

Conrad L. 2003. Five ways of enhancing the postgraduate community: Student perceptions of effective supervision and support. Proceedings of the 26th annual HERDSA (Higher Education Research and Development Society of Australasia) conference, Learning for an unknown future: Research and development in higher education. Christchurch, New Zealand: University of Otago.

Denscombe M. 2007. The good research guide for small-scale social research projects. Berkshire: Open University Press.

El Gaidi K. 2014. The journeyman as a metaphor for developing skills in postgraduate education: Experience, feedback and role models. In: E Bitzer, R Albertyn, L Frick, B Grant \& F Kelly (eds). Pushing boundaries in postgraduate supervision. Sun Press: Stellenbosch. 153-165.

Grant B. 2005. Fighting for space in supervision: Fantasies, fairytales, fiction and fallacies. International Journal of Qualitative Studies in Education, 18(3):337-354.

Green B. 2005. Unfinished business: Subjectivity and supervision. Higher Education Research \& Development, 24(2):151-163.

Guerin C, Picard M \& Green I. 2014. A coordinated framework for developing researchers' intellectual competency. In: E Bitzer, R Albertyn, L Frick, B Grant \& F Kelly (eds). Pushing boundaries in postgraduate supervision. Sun Press: Stellenbosch. 169-184.

Hemer SR. 2012. Informality, power and relationships in postgraduate supervision: Supervising PhD candidates over coffee. Higher Education Research \& Development, 31 (6): 1-13.

Leonard D. 2010. The doctorate in the life course. In: M Walker \& P Thomson (eds). The Routledge doctoral supervisor's companion: Supporting effective research in education and the social sciences. Oxon: Routledge. 171-184.

Lessing AC \& Schulze S. 2002. Postgraduate supervision and academic support: Students' perceptions. South African Journal of Higher Education, 16(2):139-149. 
Malfroy J. 2005. Doctoral supervision, workplace research and changing pedagogic practices. Higher Education Research \& Development, 24(2):165-178.

Manathunga C. 2007. Supervision as mentoring: The role of power and boundary crossing. Studies in Continuing Education, 29(2):207-221.

Maxwell TW \& Smyth R. 2011 . Higher degree research supervision: From practice toward theory. Higher Education Research \& Development, 30(2):219-231.

Morrison-Saunders A, Moore SA, Hughes M \& Newsome D. 2010. Coming to terms with research practice: Riding the emotional roller-coaster of doctoral research studies. In: $M$ Walker \& P Thomson (eds). The Routledge doctoral supervisor's companion: Supporting effective research in education and the social sciences. Oxon: Routledge. 206-218.

Pearson M \& Brew A. 2002. Research training and supervision development. Studies in Higher Education, 57(2): 135-150.

Phillips E \& Puh DS. 2005. How to get a PhD: A handbook for students and their supervisors. Berkshire: Open University Press.

Sambrook S, Stewart J \& Roberts C. 2008. Doctoral supervision ... a view from above, below and the middle! Journal of Further and Higher Education, 32(1):71-84.

Trigwell K. 2010. The relationship between doctoral students' approach to research and experiences of their research environment. In: M Walker \& P Thomson (eds). The Routledge doctoral supervisor's companion: Supporting effective research in education and the social sciences. Oxon: Routledge. 282-291.

University of Cambridge. 2015. The PhD: Supervision, advisors, expectations. [Retrieved 29 October 2015] http://www.hist.cam.ac.uk/graduate-students/phd/phd-handbook/thephd-supervision-advisors-expectations

University of Warwick. 2007. Centre for Cultural Policy Studies. What former PhD students say. [Retrieved 29 October 2015] http://www2.warwick.ac.uk/fac/arts/theatre_s/cp/applying/ phd/former_phd_students/

Vitae: Realising the potential of researchers. 2016. Professional development for researchers. [Retrieved 29 October 2015] https://www.vitae.ac.uk/researchers-professionaldevelopment/about-the-vitae-researcher-development-framework/the-vitae-researcherdevelopment-statement

Waghid Y. 2007. Education, responsibility and democratic justice: Cultivating friendships to alleviate some of the injustice on the African continent. Educational Philosophy and Theory, 39(2): 182-196.

Watts JH. 2010. Supervising part-time doctoral students: Issues and challenges. In: M Walker \& P Thomson (eds). The Routledge doctoral supervisor's companion: Supporting effective research in education and the social sciences. Oxon: Routledge. 123-130. 